\title{
artículos
}

\section{Adam Fuss: Regreso a la semilla}

\author{
Miguel Ángel Medina Torres \\ Universidad de Málaga
}

\section{RESUMEN}

La fotografía artística de Adam Fuss se caracteriza en lo formal por una exploración de las posibilidades expresivas de la fotografía sin cámara (fotogramas y daguerrotipos), al tiempo que en su temática conjuga abstracción y realismo, vida y muerte, instantaneidad y movimiento, solidez y evanescencia. Este trabajo revisa la obra de Fuss, analiza su contribución al arte de la fotografía y explora influencias y precedentes, así como el pensamiento del autor.

PALABRAS CLAVE: Fotografía/ cámara oscura/ fotograma/ daguerrotipo.

Adam Fuss: Return to the seed

ABSTRACT

Adam Fuss' artistic photography explores the expressive possibilitiesof photography without camera (photograms and daguerreotype). Its subjects combine abstraction and realism, life and death, instantaneousness and movement, solidity and evanescence. This work reviews Fuss' artwork, analyzes his contribution to the art of photography and explores influences and precedents, as well as the author's thoughts.

KEY WORDS: Photography/ pinhole camera/ photogram/ daguerrotype.

En el panorama de la fotografía contemporánea, la obra de Adam Fuss (1961) representa un singular contraste, particularmente desde el punto de vista técnico pero también temática y conceptualmente. La reciente exposición retrospectiva organizada por la Fundación Mapfre (Madrid, del 26 de enero al 17 de abril de 2011) ha brindado por primera vez la oportunidad de contemplar en España una amplia muestra con 50 obras originales representativas de las diversas técnicas y series que el autor ha desarrollado desde 1986 hasta la actualidad. La gran singularidad de la obra fotográfica de Adam Fuss es la recuperación y reinterpretación de técnicas fotográficas primigenias, particularmente el fotograma y el daguerrotipo. Al menos desde la publicación del ya clásico ensayo Entropy and Art (Arnheim, 1971), los conceptos científicos de la Termodinámica han sido frecuentemente transpuestos para su utilización en estudios sobre Arte. Más allá de las imprecisas sobreinterpretaciones que de tales conceptos científicos se hace en el campo de las artes, hay que reconocer la gran fuerza metafórica que tales conceptos adquieren una vez recontextualizados. Así ocurre con la noción de cero absoluto, a partir de la cual en algunos ensayos sobre arte se introduce el

* MEDINA TORRES , Miguel Ángel: “Adam Fuss: Regreso a la semilla”, en Boletín de Arte n 32-33, Departamento de Historia del Arte, Universidad de Málaga, 2011-2012, págs. 479-492. Fecha de recepción: Mayo de 2011. 
concepto de grado cero para referirse al nivel más primigenio y "puro" de un arte ${ }^{1}$. Pues bien, la evolución primera de las investigaciones fotográficas de Adam Fuss en sus primeros años muestra claramente un camino que le conduce hacia el que podría denominarse grado cero de la fotografía, aquél en el que la fotografía se desprende de todo tipo de artefacto intermediario (sea este una cámara oscura o una cámara fotográfica) entre la luz, el objeto expuesto a la luz y el material fotosensible.

Con motivo de la exposición retrospectiva antes mencionada, la Fundación Mapfre ha editado un lujoso catálogo precedido por un interesante ensayo firmado por la comisaria de la exposición CherylBrutvan y cuyo apartado introductorio aparece titulado de forma evocadora "Regreso al jardín"2. Hasta el momento, este texto es, junto con el artículo-entrevista “¿Qué es abstracto?” publicado años atrás en la revista Exit ${ }^{3}$ y junto con el ensayo de Bucklow que cierra el catálogo ${ }^{4}$, uno de los tres únicos textos breves monográficos dedicados a la obra de Fuss disponibles en español. De forma retrospectiva, puede considerarse esta exposición monográfica una excelente excusa para revisar al autor y su obra, objetivo que persigue el presente trabajo.

\section{EL AUTOR.}

Adam Fuss nació en Inglaterra en 1961. Hijo de un fabricante de abrigos muerto prematuramente en 1968 y de una modelo australiana, vivió con su madre en Australia en los periodos 1967-70 y 1971-73. En 1980 regresó a Australia.

Aunque se suele citar en sus notas biográficas que hizo su primera fotografía con 3 años y medio ${ }^{5}$, una foto de su niñera embarazada dando de comer a un pájaro que se está posando en su mano, el propio Fuss declara que dicha fotografía no tiene nada que ver con el hecho de que se convirtiera en fotógrafo. Es más, apunta que no supo nada de ella hasta treinta años después.

Sus primeras inquietudes intelectuales le llevaron a sentirse atraído por las ciencias. No fue hasta su adolescencia cuando, tras realizar ensayos con el equipo fotográfico y el laboratorio de revelado de su escuela, empezó a interesarse en la fotografía, como puente hacia el mundo de las artes, la literatura y el cine.

A través de los contactos de su madre con las agencias y fotógrafos de Australia, comenzó su carrera como aprendiz de fotógrafo para la Agencia Ogilvy\&Mather. Durante este tiempo, recibió clases de fotografía de Graham Mc Carther, quien organizaba sesiones de diapositivas en las que mostraba fotografías de las primeras figuras históricas del medio de las que Fuss tuvo conocimiento: Ralph Eugene Meatyard, EugèneAtget y Bill Brandt, siendo la obra de este último la que más le impresionó.

1 Así, el profesor Eugenio Carmona se refiere frecuentemente al momento del cubismo picassiano en el que el genio alcanza el grado cero de la pintura.

2 BRUTVAN, C. "Adam Fuss", en AA. VV.: Adam Fuss. Madrid, Fundación Mapfre, 2011, págs. 15-35.

3 VICENTE, M. “¿Qué es abstracto?”. Exit: Imagen y cultura, n²14, Marid, 2004, págs.. 38-53.

4 BUCKLOW, C. "El niño llega suavemente como la nieve", en AA. VV.: Adam Fuss. Madrid, Fundación Mapfre, 2011, págs. 159-171.

5 "Una imagen increíble", en palabras de Mercedes Vicente. En VICENTE M, op. cit. 
Trabajando como fotógrafo comercial, se hizo pronto consciente de que ese no era su camino, que no era eso lo que buscaba en la fotografía y en su vida. Decidido a romper con lo que, por aquellos tiempos, llamaba "la cultura tecnológico-consumista", dejó su trabajo y se mudó, primero a Inglaterra, y poco después (ya en 1982) a Nueva York, donde sigue residiendo en la actualidad. En vez de volar directamente de Londres a Nueva York, escogió volar hasta Alaska y realizar luego un extenso periplo terrestre a través a través de bravíos parajes canadienses y de la frontera norte de los estados Unidos. Nueva York no era en esos tiempos la pujante y segura capital turística que es actualmente; era una ciudad mucho más áspera y oscura, desgajada por la lacra de las drogas y sus secuelas y con zonas enteras de algunos distritos (como Williamsburg en Brooklyn y Harlem en Manhattan) ocupadas por decrépitos edificios abandonados. Precisamente los edificios abandonados de Williamsburg se convertirían en objeto de estudio durante las primeras experiencias fotográficas de Fuss en la ciudad que se convirtió a partir de entonces en su hogar. Prefirió sobrevivir económicamente con trabajos ocasionales fuera del campo de la fotografía, tales como camarero en un "art-cafe" y para celebraciones en el MetropolitanMuseum, mientras se iniciaba en su camino de experimentación que le llevó a ir desprendiéndose de "aditamentos", un camino de "regreso a la semilla"6, de retorno hacia los medios fotográficos más simples. Así, sustituyó primero la cámara fotográfica por una simple cámara oscura ("pinhole camera") y, muy pronto, ésta por métodos de exposición directa de material fotosensible sin el empleo de cámara alguna. De esta forma llega a practicar con la técnica del daguerrotipo y, sobre todo, con el fotograma,su medio de expresión más habitual.

Su primera exposición fue en 1985, en la Galería MassimoAudiello de Nueva York. Desde entonces, se han sucedido innumerables exposiciones colectivas e individuales en galerías de prestigio internacional y museos. El Museo de Bellas Artes de Boston programó un gran retrospectiva de Adam Fuss ${ }^{7}$. Su obra forma parte de colecciones privadas y de museos del prestigio del Musem of Modern Art (MoMA, Nueva York), MetropolitanMuseum (Nueva York) y Victoria \& Albert Museum (Londres).

En España, expuso por primera vez en 1990, en una colectiva en la Galería Fucares de Madrid y en una exposición conjunta con Javier Baldeón en Barcelona. Al año siguiente, participó en la Exposición Internacional Anual de Santa Cruz de Tenerife. Hasta el momento de la gran retrospectiva de Madrid de 2011, sólo había presentado exposiciones individuales en dos ocasiones: En la Galería Leyendecker de Tenerife en 2005 y, más recientemente, en la Galería Marta Cervera de Madrid ${ }^{8}$.

6 Se alude aquí al título de un relato breve del escritor cubano Alejo Carpentier, en el que se narra la vida completa de un personaje empezando en el momento de su muerte y terminando en el momento de su concepción. En el contexto de este estudio, la expresión "regreso a la semilla" hace referencia al viaje de Fuss en busca de las técnicas fotográficas más "simples" y "puras", de los inicios de la propia historia de la fotografía.

7 A finales de 2002 y hasta el 12 de enero de 2003. Con motivo de esta exposición, se realizó una de las más difundidas entrevistas a Adam Fuss.

8 Hasta el 5 de diciembre de 2008. Esta misma galerista ya había presentado obras de Fuss en su galería de Nueva York en una exposición colectiva en 1989. 


\section{SU OBRA Y SU TÉCNICA.}

\section{FotograFíA CON CÁMARA.}

Fuss comenzó sus experimentaciones haciendo uso todavía de una cámara fotográfica convencional. En su breve periodo de tránsito en Inglaterra entre Australia y Nueva York, trabajó con la cámara, moviéndola y tomando fotos a la vez que utilizaba el flash. Con el movimiento, usando la cámara a velocidad 1/60 (la usual cuando se emplea el flash), se genera una imagen borrosa, sobre la cual aparece una imagen definida sobreimpresionada recogida al saltar el flash. De esta forma, se obtiene un resultado dual y, con ello, ambiguo; si se quiere, un tanto "fantasmagórico".

Desafortunadamente, no conocemos esas imágenes porque nunca se reprodujeron. Sólo contamos con el testimonio del propio autor, quien reconoce que esa técnica la copió de John Williams y apunta que siguió trabajando de esa forma en sus primeros tiempos en Nueva York, fotografiando entre los edificios abandonados de Williamsburg (Brooklyn). Alli fue aún más lejos, disparando el flash varias veces seguidas y generando imágenes que, en palabras del propio Fuss, "parecían pinturas impresionistas".

\section{FotOGRAFÍA CON CÁMARA OSCURA.}

En la primera mitad de los años ochenta, cuando trabajaba de noche en el MetropolitanMuseum, decide abandonar la cámara convencional y empieza a practicar con la cámara pinhole ${ }^{9}$ o cámara oscura. Allí Fuss realizó toda una serie de notables fotografías en la galería de esculturas. Así lo evoca el propio Fuss en su entrevista con Mercedes Vicente:

"Me encontraba a menudo solo en la oscuridad en las galerías de escultura, rodeado de las personificaciones de dioses griegos. Durante el día, estos dioses estaban esterilizados en el ambiente del museo, pero por la noche se reavivaban. Así que la idea fue crear un ambiente fotográfico en el cual éstos se reanimaran, para devolver el espíritu a estos objetos religiosos y de culto que les había sido suprimido durante el día con la gente y las fuertes luces. En mis fotografías les devolvía ese elemento evocador"10.

\section{Fotografía SIN EL USO DE CÁmARA.}

Pronto, en su camino de experimentación, Fuss da otro salto adelante -que le lleva, al mismo tiempo, atrás, a los momentos primigenios de la fotografía 
decimonónica-. Decide abandonar el uso de las cámaras y entregarse a la fotografía directa sobre superficies fotosensibles. Recurre a los procedimientos del daguerrotipo y, sobre todo, del fotograma.

El interés de Fuss en el daguerrotipo estriba en que es una manera de hacer una fotografía que sea fresca. Este particular procedimiento de reproducción de imágenes sobre una superficie metálica pulida hace que cada daguerrotipo sea único y permanente, pero el proceso quedó muy pronto desfasado tras la introducción del procedimiento del colodión húmedo. Fuss es uno de los escasos fotógrafos actuales que han retomado este procedimiento (en su caso, desde 1999, esto es, bastante después de iniciarse en el procedimiento del fotograma), aunque no es el único, como testimonian las obras de Robert Shlaer y de ChuckClose. El interés de estos y otros fotógrafos en recuperar la técnica se basa en que los daguerrotipos ofrecen un nivel de detalle y "dimensionalidad" no superado por ningún otro procedimiento ${ }^{11}$. En palabras de Brutvan:

"El atractivo del daguerrotipo para Fuss estaba en volver a encontrar el proceso que brindase el medio idóneo para la foto que quería hacer. Impugnar las ideas tradicionales de escala y explotar la apariencia especular del objeto final eran las características de su primera serie de imágenes expuestas de una calavera"12.

Sin embargo, los daguerrotipos de Fuss no siempre han tenido buena crítica. Así, con motivo de la exposición MyGhost en la Cheim\&ReadGallery de Nueva York, una crítica reseñaba:

"Sus resurrecciones de la técnica del daguerrotipo son de una manera extraña impecables y superficiales, poco más que vagas imágenes en un espejo, lo cual sugiere que las prácticas obsoletas del pasado no pueden ser recuperadas auténticamente"13.

Pero si algo caracteriza la obra fotográfica de Adam Fuss es su virtuoso dominio de la técnica del fotograma y las diversas vías de exploración por las que ha ido expandiendo sus posibilidades. El fotograma no requiere del uso de cámaras ni negativos, pues hace uso exclusivamente de papel fotosensible y una fuente de luz proyectando sombras o reflejos sobre la superficie del soporte. Las sombras las generan los objetos que se interponen entre la fuente de luz y el soporte, en muchas ocasiones en íntimo contacto físico con éste. Al tratarse de reproducciones de sombras, las exigencias técnicas se acentúan, pues el control de la intensidad y tiempo de exposición es clave

11 Adam Fuss opina: "El daguerrotipo es muy superior a los procesos que vinieron después, su imagen es más definida y capta mucha más información. Es como si la fotografía hubiese comenzado con el RollsRoyce y acabase en un Honda. Me resulta también atractiva porque es la encarnación del misterio y de la química de la fotografía”. Tomado de la entrevista recogida en: VICENTE M. “¿Qué es abstracto?”. Exit: Imagen y cultura 14: 38-53, 2004

12 En BRUTVAN, C., op. cit.,, pág. 32.

13 SMITH R. Adam Fuss- "My Ghost". The New York Times.SecciónArt in Review.Publicado el 17 de septiembre de 1999. 
para el resultado final. Además -y más que en cualquier otra técnica fotográfica-, el trabajo intelectual de composición previa preacondiciona decisivamente el resultado ${ }^{14}$.

Los fotogramas de Adam Fuss son completamente diferentes a cualquier otro fotograma hecho previamente. En este sentido, es plenamente original. También es radicalmente experimentalista, expandiendo las posibilidades del fotograma y liberándolo del reino de sombras en blanco y negro. Sus fotogramas en blanco y negro son estudios dinámicos de luces y formas. Su uso del papel Cibachrome con sus tres capas de emulsiones sensibles a cada uno de los tres colores primarios le permite explorar territorios ignotos en los que sombra y color conviven, en equilibrio (de nuevo, dinámico) de luz y color. Fuss fija magistralmente la fugacidad del momento único, el movimiento, el cambio, usando la luz como metáfora para iluminar los procesos y las etapas de la vida.

\section{SUS SERIES.}

Las obras de Fuss, mayoritariamente sin título, se agrupan en grandes series que se extienden y desarrollan en el tiempo. Aquí se hará mención sólo de algunas de las más destacadas.

- La serie de fotogramas realizada con flores pueden recordar a los fotogramas naturalistas de Henry Fox Talbot y Anna Atkins, quienes también experimentaron exponiendo plantas a la luz. Sin embargo, Fuss niega ningún tipo de influencia de estos autores, a los que reconoce que desconocía cuando empezó con sus experimentos. Por lo demás, él recompone la imagen de flores quiméricas, hechas con partes procedentes de diversos tipos de flores y genera imágenes de vívidos colores.

- La serie de las serpientes, que recoge el rastro de su movimiento ondulante en el agua o sobre talco, generando una viva sensación dinámica. En estos fotogramas está particularmente remarcada la tensión entre las necesidades (y finalidades) estéticas del artista y el caos (o, tal vez, azar) introducido por lo impredecible del sentido del movimiento de la serpiente viva [1].

- La serie de daguerrotipos de calaveras humanas [2] que representó la parte central de su exposición de 2003 en la Cheim\&ReadGallery de Nueva York, y que volvería a la misma galería en 2007 para formar parte de la interesante exposición colectiva I Am as YouWill Be: TheSkeleton in Art. Con motivo de la primera exposición de esta serie, un crítico certeramente observó:"Cada superficie es tan reflectante y argentada que contemplar el memento mori es también mirar tu propia cara"15.

- La serie Ark $^{16}$, que recoge las ondas generadas en el agua al caer sobre ella una o varias gotas del mismo líquido [3]. Es una de las series iniciadas más pronto (en 1987) y de más extenso desarrollo, hasta llegar a las extraordinarias imágenes de gran tamaño fechadas a partir de 2007 [4].

14 Por tanto, y en contraste con muchas técnicas fotográficas más modernas, el procedimiento del fotograma requiere un máximo nivel de aportación artística, pues el artista ha de controlar todos los detalles.

15 SCHEJDAHL, P. "Adam Fuss", The New Yorker, Nueva York, 3 de noviembre de 2003.

16 Con este título, Adam Fuss hace alusión al Arca de Noé. 


\begin{tabular}{|c|c|}
\hline 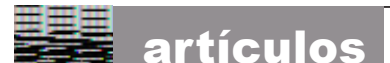 & Adam Fuss: Regreso a la semilla \\
\hline
\end{tabular}

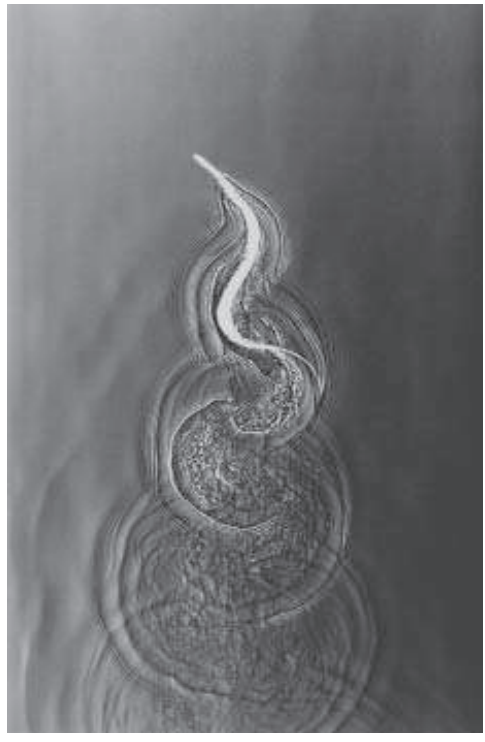

1. Sin título, 2007. Fotograma (gelatina de plata). Ejemplar único, 209,6x147,6 cm.Cheim\&Reid, Nueva York. (Archivo Adam Fuss AF0412).

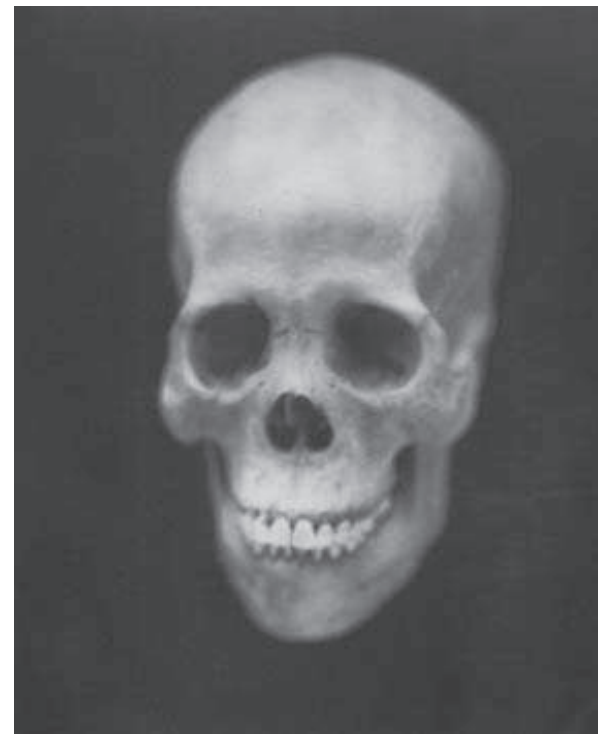

2. Sin título, 2002. Fotograma (gelatina de plata). Ejemplar único, $35,6 \times 27,9 \mathrm{~cm}$. Colección privada. (Archivo Adam Fuss AFD101).

- La heterogénea serie MyGhost, en la que juega con el blanco y negro en cuatro subseries: A) Daguerrrotiposy fotogramas de retratos-siluetas. B) Fotogramas negativos y daguerrotipos de trajes de bautizo antiguos, en los que los encajes crean una imagen como de de finas líneas blancas trazadas sobre papel oscuro [5]. C) Siluetas de pequeñas bandadas de pájaros en vuelo [6], que recuerdan a las pinturas sentimentales de Ross Bleckner. D) Quizás la subserie más impresionante sea la formada por grandes fotogramas en los que Adam Fuss captura la eruptiva y agitante energía del humo, consiguiendo dar a lo casi etéreo una inquietante y estremecedora solidez.

- La muy popular serie Invocation, iniciada en 1992, en la que capta imágenes de bebés flotando en el agua. Vistos como desde abajo, los bebés parecen precariamente a salvo, jugueteando y levitando en anillos de agua e inmersos en un halo de dorado color "solar" surgido a partir de las propiedades del papel Cibachrome. Estos extraordinarios fotogramas pueden recordar imágenes obtenidas por amniografía de fetos inmersos en el líquido amniótico de su madre. Una de las fotografías únicas de esta serie forma parte del Victoria and Albert Museum. En ella, el bebé aparece suspendido en el centro de un fondo de vivo amarillo. Su cabeza gira hacia arriba y sus brazos se mantiene doblados en uve, como equilibrando su cuerpo. El bebé descansa con las piernas separadas y dobladas por las rodillas. El reflejo del bebé en 


\begin{tabular}{|c|c|}
\hline EE & Miguel Ángel Medina Torres \\
\hline
\end{tabular}

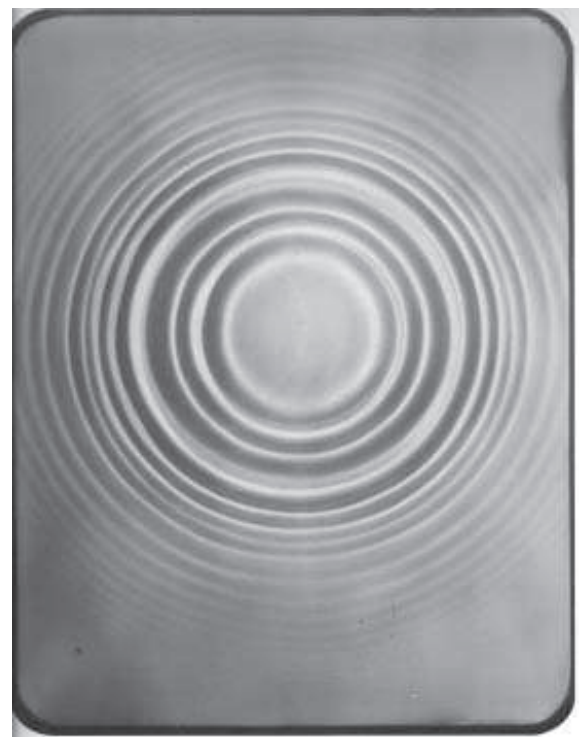

3. De la serie Ark, 2004. Daguerrotipo. 35,6x27,9 cm. Timothy Taylor Gallery, Londres. (Archivo Adam Fuss AFD179).

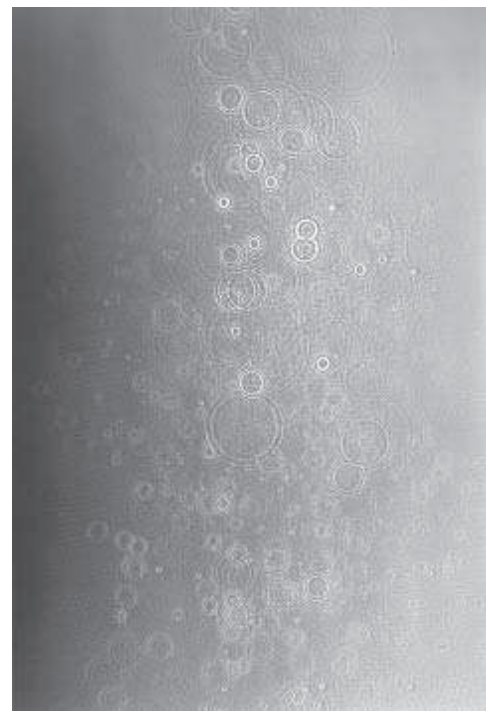

4. Sintitulo,2007. Fotograma (gelatina de plata). Ejemplar único, 209,9x147 cm. Galería Marta Cervera, Madrid. (Archivo Adam Fuss AF4055).

el agua crea cuatro anillos rotos detrás y debajo de su pierna derecha y seis debajo de su codo derecho. La imagen resultante tiene cualidades escultóricas, por cuanto alcanza su máxima oscuridad justo donde el bebé estuvo tocando directamente el papel, imposibilitando que la luz alcanzase esa zona.

- La serie Mary, de 1995-6, en la que usa fragmentos de hígado recién eviscerado de vaca, generando unas imágenes con vivos contrastes de color $^{17}$.

- La serie anterior llegó en un momento en que el público ya se había enfrentado a otras obras polémicas y provocadoras en las que Adam Fuss había generado imágenes intensamente coloristas a partir de las reacciones químicas de las vísceras con el Cibachrome. Paradigma de ello son las series Lovey Details of Love, iniciadas en 1992 en un momento emocionalmente tumultuoso en la vida del artista. De hecho, Fuss confiesa que uno de los motivos por los que surgió la serie fue a partir de un trauma personal. Su explicación no deja de ser curiosa: "Existe una conexión muy fuerte entre las emociones y los intestinos, así que tenía que trabajar con intestinos"18. Así que, dicho y hecho: El famoso y muy reproducido fotograma Love (1992; 100,3×75

17 La serie presente ser un conjunto de "retratos" de la Virgen María generados por las reacciones químicas que se producen al entrar en contacto las emulsiones del papel Cibachrome con las vísceras. En su estudio de la obra de Fuss, James Crump afirma que estas imágenes son "a la vez divinas y grotescas, reverenciales y blasfemas".

18 En VICENTE M, op. cit. 


\begin{tabular}{|c|c|}
\hline 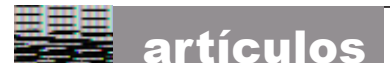 & Adam Fuss: Regreso a la semilla \\
\hline
\end{tabular}
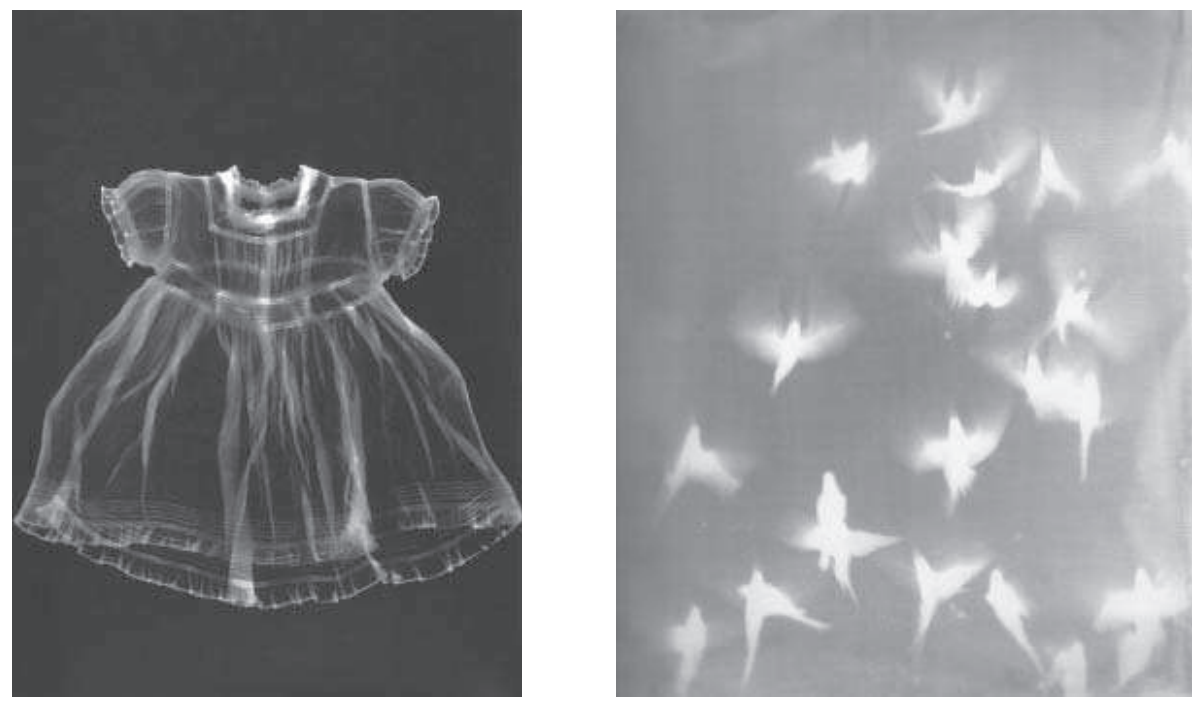

5. Sin título, de la serie MyGhost, 2001. Fotograma (gelatina de plata). Ejemplar único, $89 \times 74,4 \mathrm{~cm}$. Colección privada.

6. Sin título, de la serie MyGhost, 1998. Fotograma (gelatina de plata). Ejemplar único, 135,9x101,6 cm. Cheim\&Reid, Nueva York. (Archivo Adam Fuss AF716).

$\mathrm{cm}$ ) resultó del contacto directo con el papel Cibachrome de dos conejos muertos de los que evisceró sus paquetes intestinales, que dispuso en cuidadosa composición y a los que dejó reaccionar con las emulsiones del papel fotográfico durante varias horas antes de proceder a la iluminación mediante flash de todo el conjunto y continuar con un revelado convencional. La reproducción de la imagen en la revista de fotografía Aperture en 1994 generó un fuerte debate en el que se alzó la voz airada y crítica del fotógrafo Robert Adams, escandalizado por el uso de las entrañas de animales.

- La reciente serie ForAllegra (2009) ofrece, entre otras imágenes, delicadas reproducciones de mariposas.

- La más reciente de sus series, Home and the World (2010), consta de daguerrotipos y fotogramas de gran tamaño en los que frecuentemente cuerpos retorcidos de serpientes cobran protagonismo [7].

\section{La contribución de Adam Fuss al arte de la fotografía.}

En su búsqueda de la pureza fotográfica, Adam Fuss fue despojando su equipo de todo lo prescindible hasta llegar a lo básico, hasta regresar a la semillade las primitivas técnicas de la fotografía directa sin cámara. Pero no lo hace con un afán meramente 


\begin{tabular}{|c|c|}
\hline 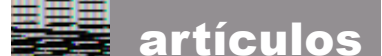 & Miguel Ángel Medina Torres \\
\hline
\end{tabular}

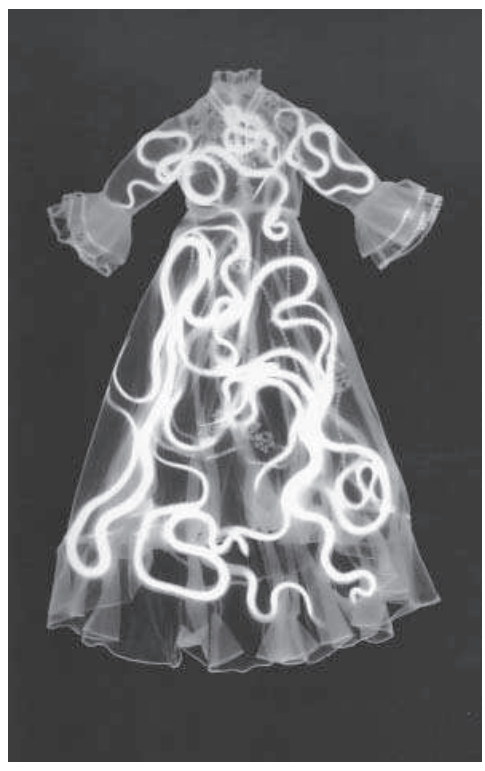

7. Medusa, de la serie Home and theWorld, 2010. Fotograma (gelatina de plata). Ejemplar único, 240x144,1 cm. Timothy Taylor Gallery, Londres. (Archivo Adam Fuss AFS97.3). imitativo, sino genuinamente experimental, desarrollando nuevos caminos para el fotograma, aprovechando las posibilidades de los modernos papeles fotosensibles, probando su sorprendente reactividad química con materia orgánica y dotando a todo el conjunto de un coherente equilibrio de precisa composición, virtuosismo técnico y sensibilidad artística. De esta forma, Adam Fuss ha creado una obra artística que está expandiendo de forma continua los parámetros del fotograma, llevándolo más allá, en términos de contenido, técnica e intensidad emocional. El fotograma es el reino de las sombras, lo que el fotograma capta son siluetas, pero Fuss consigue incluir matices lumínicos y/o cromáticos en ellas como nunca nadie antes había logrado.

Suelen coincidir los críticos de arte al describir la obra de Fuss como la representación de temas que hacen referencia a lo efímero del momento, a la fugacidad y fragilidad de lo vivo. Para James Crump, la obra de Fuss sugiere nuevas forma de pensar acerca del medio fotográfico, su historia y cómo puede usarse de modo inteligente para abrir una nueva vía a la imagen fotográfica. Según Amelia Jones, Fuss explota inexploradas capacidades estéticas del fotograma, particularmente aquellas que transforman objetos y sustancias en siluetas fantasmales y efímeras de "lo real". En palabras de Elena Vozmediano, la obra de Fuss está impregnada del deseo de captación de un "algo más" que raramente se encuentra en la fotografía convencional: el residuo de un contacto con la vida, que queda retenida (siquiera sea de alguna manera y en pequeña medida) en el papel. Roberta Smith señala que la mayor fortaleza de la obra de Fuss es el imponente derroche visual surgido de una combinación de "azar controlado" puro y un control prodigioso.

La obra de Fuss ha sido catalogada de viscera/ ${ }^{19}$. Para el galerista Xavier Hufkens, Adam Fuss es uno de esos escasos artistas que consiguen realizar imágenes que tienen un efecto penetrante en quienes las observan. $Y$ añade que su poderosa capacidad imaginativa se despliega completamente en su obra, que tiende hacia la abstracción pero manteniendo igualmente trazas de vitalidad orgánica.

Los fotogramas de Fuss tienen una cualidad aditiva, antes que sustractiva.

19 El apelativo puede aplicársele tanto en sentido figurado como literal. 
En ellos, la textura, el color y el movimiento desplazan las convenciones fotográficas tradicionales de foco, profundidad de campo y marco de composición. Adam Fuss conjuga en su obra abstracción y realismo, vida y muerte, instantaneidad y movimiento, solidez y evanescencia. En definitiva, en palabras de James Crump, "Io que hace a Fuss tan excepcional es la rara consistencia temática y filosófica de toda su obra" ${ }^{20}$.

Su PENSAmiento. Influencias, PRECEDentes y compañeros de Viaje.

El pensamiento de Adam Fuss en relación con su propia obra, la fotografía artística y el arte en general queda explicitado en las diversas entrevistas que ha concedido.

Siendo el fotograma el medio de expresión más frecuentemente empleado por Fuss en su obra artística, se hace casi inevitable mencionar como posibles antecedentes los fotogramas de los vanguardistas Christian Schad, ManRay y Moholy-Nagy, o incluso los trabajos precursores de Henry Fox Talbot y de Anna Atkins en la primera mitad del siglo XIX. Sin embargo, estas conexiones inmediatas son demasiado simplistas. De entrada, Fuss no tiene problema en reconocer su falta de formación histórica: sin estudios universitarios, jamás cursó una historia de la fotografía y durante sus primeros años de experimentación sencillamente desconocía la obra de esos predecesores. De forma que niega cualquier tipo de influencia de los fotogramas con plantas de Talbot y Atkins. Fuss declara que, en todo caso, su auténtica afinidad con estos dos precursores está en su interés por el mundo de la naturaleza y no en la fotografía. Así pues, su afinidad por la naturaleza lo acerca en espíritu a los dos precursores decimonónicos, pero técnicamente tal vez algunos de sus fotogramas tengan más que ver con los que realizaron los vanguardistas. Sin embargo, hay que señalar que Fuss declara explícitamente que no le interesa la obra de ManRay. Artísticamente, le atrae mucho más el expresionismo abstracto de Jackson Pollock porque "sus pinturas son directas, no hay nada intermedio en ellas"21. O sea, Fuss admira las obras artísticas directas y con el mínimo de manipulación (si fuere posible, sin ninguna manipulación). Él también busca expresarse en su obra sin manipulaciones. Esa búsqueda es la que le llevó a abandonar la cámara y abrazar la técnica del fotograma:

"La cámara reproduce pero se da una manipulación, pero con el fotograma no hay manipulación (...) yo no creo que el control de la luz en el fotograma sea una manipulación de la estructura de la imagen"22.

Esta búsqueda del arte (de la fotografía directa) sin manipulación se relaciona con su búsqueda de "la Verdad" en su obra, verdad que el propio Fuss identifica con "honestidad". Curiosamente (o no), "honestidad" es una palabra que repetidamente

20 CRUMP J. Visceral photography: the work of Adam Fuss. Afterimage. Julio-Agosto, 1997.

21 En VICENTE M, op. cit.

22 En VICENTE M, op. cit. 
emplea Beaumont Newhall para referirse a la obra de algunos de los principales representantes de la denominada fotografía directa (pero -jojo!- empleando cámara) norteamericana de la segunda década del siglo XX. Aunque en los textos consultados $y$ utilizados en este trabajo no he encontrado ninguna referencia que ligue a Fuss con estos fotógrafos históricos, tengo la convicción de que es razonable postular afinidades entre la forma de entender la fotografía de Fuss y la de Strand, Sheeler o Weston. De la obra fotográfica de Paul Strand se suele destacar su vanguardista sentido de la abstracción al tiempo que su profundo lirismo. Estos criterios pueden usarse para calificar la obra de Fuss, quien aspira a un romanticismo de nuevo cuño que busca la Belleza en la Verdad, creando en dicha búsqueda imágenes utópicas. Conviene recordar aquí que Paul Strand escribió: "La honestidad se constituye en requisito previo de una expresión viva"23. Y que en 1916-7 generó poderosas abstracciones geométricas a partir de fotografiar directamente elementos de la realidad. Por su parte, Charles Sheeler fotografió con evidente honestidad creando una sensible interpretación sobre formas y texturas de obras humanas. Y, para terciar, Edward Weston escribió: "No dejaré pasar la oportunidad de registrar una abstracción interesante, pero me siento firme en mi creencia de que la tendencia de la fotografía es a través del realismo"24. Como Alfred Stieglitz, Adam Fuss busca la Verdad. Y lo hace identificándola con la honestidad, como el requisito previo que Strand sugiere para una expresión viva y que aplican Sheeler y Weston a su obra. Y, como Strand y Weston, en el histórico pulso entre abstracción y figuración, Adam Fuss se posiciona considerando que -al menos, en fotografía- toda abstracción surge a partir de la realidad representada. Con esto, llegamos a lo que Rosa Olivares ha denominado "el enigma de la abstracción". Si para Gauguin todo arte es abstracto, por cuanto la percepción subjetiva que cualquier artista realiza en una obra la aleja de la realidad para transformarla en "otra cosa", ¿qué decir de la fotografía? Adam Fuss en este punto es categórico: puesto que la fotografía (cualquier fotografía, toda fotografía) es la fijación y reproducción de la luz y algún objeto real, no hay abstracción posible en la fotografía. Pero inmediatamente matiza y reconoce: "Estoy fascinado por la abstracción y he pensado mucho en ella en relación con la fotografía y su significado en ella, sobre qué es lo que podría distinguirse como una fotografía abstracta"25. Sin embargo, piense lo que piense Fuss, un repaso a la historia de la fotografía muestra que, de hecho, la fotografía abstracta es una corriente que existe desde sus inicios como lenguaje artístico. Los vanguardistas como ManRay o Moholy-Nagy se planteaban la fotografía como un método de búsqueda. Por su parte, Adam Fuss ha explorado y buscado en sus experimentaciones fotográficas un medio a través del cual transforma objetos y sustancias en siluetas fantasmales y efímeras de "lo real", como ya queda dicho más arriba. La realidad reiterada de su obra nos habla -más que él mismo- de su dinámico movimiento entre abstracción y representación. De hecho, el propio Fuss reconoce

23 Citado en NEWHALL B. Historia de la Fotografía. Gustavo Gili. Barcelona, 1983.

24 Citado en NEWHALL B, op. cit.

25 En VICENTE M, op. cit. 
que en su obra emblemática Love "quería hacer una imagen que comprendiese las cualidades de la figuración y de la línea abstracta dentro de la misma fotografía" ${ }^{26}$.

Quienes han estudiado la obra de Fuss reconocen unánimemente su prodigioso control de los aspectos técnicos y compositivos. El propio autor apunta: "Cuando yo creo una imagen soy muy puntilloso con la cantidad de luz y controlo dramáticamente la situación". Sin embargo, este control -que él necesita- lo siente, al mismo tiempo, como su más reiterado "fracaso". Cuando se le pregunta "¿Qué fracaso?", señala: "El intentar construir demasiado una estructura estética". Y ello porque, señala, "me he dado cuenta de que el trabajo que más me gusta es el de aquellos artistas que lidian con el arte sin intentar ejercer un control sobre él, como Pollock o Atget". Y señala también a la más reconocida autora de fotogramas en la actualidad: "Por ejemplo, en el trabajo de SusanDerges he observado que ejerce menos control, no quiero decir que no tenga un control técnico, sino que tiene menos necesidad de arreglarlo todo, de forma casi estéril, para crear una situación perfecta". Como, a pesar de todo, no puede renunciar a mantener el control, se esfuerza en lo posible en mantener un estado de tensión entre sus necesidades artísticas y el caos. Quizás por ello se siente particularmente satisfecho con las obras en las que introduce elementos de azar irreductible; es el caso de su serie Ark, y de la serie de las serpiente, y de la serie Invocation con los bebés flotantes, e incluso en los casos en los que hace reaccionar el Cibachrome con vísceras o fluidos corporales (como en las series Mary, LoveyDetails of Love) ${ }^{27}$.

Pero volvamos a los principios fundamentales del pensamiento artístico de Adam Fuss. Como queda dicho, Fuss busca con (y en) sus obras la Verdad, que identifica o define como honestidad, y ésta la podemos entender como una faceta de la Bondad. Y aspira a crear cosas bellas. Tenemos, pues, la tríada VerdadBondad-Belleza que remite a una prolongada línea de desarrollo del pensamiento clásico, que arranca en Platón y se reinterpreta con los Neoplatónicos. Es decir, en el pensamiento estético ( $y$ también ético) de Fuss encontramos un posicionamiento neoplatónico. No es una mera especulación de quien esto escribe, pues ya en 1997 James Crump, en su ensayo sobre la obra de Fuss, señala que la misma ejemplifica una actitud neoplatónica, como también es el caso -añade- de sus colegas británicos SusanDerges, GarryFabian Miller y Christopher Bucklow.

El neoplatonismo de Fuss, como tal, es un idealismo y está estrechamente vinculado con la metafísica, también presente en su obra ${ }^{28}$. Fuss declara: "Siempre he necesitado hacer imágenes que tengan un sentido de revelación para el observador y para mí" 29 . Y parece que lo consigue: así puede justificarse -siquiera en parte- el éxito que Xavier Hufkens le atribuye en producir imágenes con efectos penetrantes en el espectador. Para Fuss, esa "revelación" tiene algo que ver con la belleza,

26 En VICENTE M, op. cit.

27 Todas las citas literales del párrafo están tomadas de nuevo de la entrevista concedida a Mercedes Vicente.

28 En palabras de CherylBrutvan: "El arte de Adam Fuss a lo largo de casi treinta años de carrera se distingue por su reveladora belleza y su carácter metafísico”. En BRUTVAN, C., op. cit., pág. 15.

29 FUSS A. Pinhole Photographs. Smithsonian Institution Press.Washington, 1996. 
con el misterio, con la categoría estética de lo sublime, claro punto que lo entronca con los postulados del Romanticismo decimonónico. James Crump es categórico al señalar que ese efecto penetrante, revelador, que la imágenes creadas por Fuss producen en el espectador son avatares, en el sentido que el término adquiere nada menos que en la obra de Joseph Beuys; avatares que apuntan al viaje espiritual e intelectual del artista como pocas obras han conseguido.

Un prodigio de equilibrio entre estricto control y azar, entre abstracción y figuración, entre visceralidad y espiritualidad, entre lo científico y lo metafísico, de variedad y al mismo tiempo consistencia temática y filosófica, la obra de Adam Fuss no deja indiferente a quien la observa y puede ser contemplada en estos inicios del siglo XXI como un serio, honesto y arriesgado intento de renovar la fotografía abriéndole nuevo caminos desde su más primigenia esencia, regresando a la semilla. El legendario Alfred Stieglitz escribió: "La fotografía es mi pasión... La búsqueda de la Verdad es mi obsesión”. Adam Fuss podría asumirlas plenamente. 